\title{
ALÉM DO QUE SE VÊ: O DESENHO DE ALUNOS CEGOS COMO FORMA DE REPRESENTAÇÃO DE SUAS IMAGENS MENTAIS
}

\author{
Patrícia Assis da Silva ${ }^{1}$ \\ Silvia Elena Ventorini
}

\begin{abstract}
Resumo: Neste artigo é apresentado um recorte da dissertação de mestrado intitulada "O estudo da organização e representação espacial de alunos cegos para o ensino de conceitos cartográficos". O objetivo é apresentar a experiência vivenciada durante a coleta de dados por meio dos desenhos. O público-alvo foram seis alunos cegos do $7^{\circ}$ ano do Instituto São Rafael. O procedimento teóricometodológico teve como base a Perspectiva Sociocultural. Os dados foram coletados individualmente e utilizou-se uma folha A4 e uma caneta 0.7 milímetros como material de apoio. Os resultados indicaram que em suas representações, os sujeitos utilizaram a distância funcional, organização configuracional, relações espaciais entre os objetos e informações atributivas. Esses conceitos podem ser utilizados para mediar alguns conceitos cartográficos como escala, orientação, legenda e representação bidimensional. Conclui-se que é importante trabalhar com locais próximos ao cotidiano dos educandos cegos e partir de situações problemas que os instiguem a refletir sobre as relações espaciais entre os objetos.
\end{abstract}

Palavras-chave: Desenhos; Crianças Cegas; Representação; Conceitos Cartográficos; Ensino.

\section{BEYOND WHAT IS SEEN: THE DRAWING OF BLIND STUDENTS AS FORM OF REPRESENTATION OF THEIR MENTAL IMAGES}

\begin{abstract}
In this study, a cut of a dissertation entitled "The study of the organization and spatial representation of blind students for the teaching of cartographic concepts". The objective is to present the experience lived during the data collection through the drawings. The target audience was six blind students of the 7th year of the São Rafael Institute. The theoretical-methodological procedure was based on the Sociocultural Perspective. The data were collected individually and an A4 sheet and a $0.7 \mathrm{~mm}$ pen were used as support material. The results indicated that in their representations, the subjects used functional distance, configurational organization,
\end{abstract}

\footnotetext{
${ }^{1}$ Doutoranda em Geografia na Universidade Federal de Minas Gerais. patriciaassis.geo@gmail.com

2 Docente no Programa de Pós-Graduação em Geografia da Universidade Federal de São João del-Rei. sventorini@ufsj.edu.br
} 
spatial relations between objects and attributive information. These concepts can be used to mediate some cartographic concepts such as scale, orientation, legend and two-dimensional representation. It is concluded that it is important to work with places close to the daily life of the blind students and to start from situations that encourage them to reflect on the spatial relations between objects.

Keywords: Drawings; Blind Children; Representation; Cartographic Concepts; Teaching.

\section{INTRODUÇÃO}

A palavra desenho possui uma definição abrangente no dicionário. Existem algumas semelhanças entre grafia, fonética, ou até mesmo no significado entre desenho e escrita, para algumas culturas e povos. Os indígenas da tribo de Siona, da Colômbia e do Equador utilizam a mesma palavra para se referir tanto à escrita como ao desenho. Em algumas línguas da cultura oriental e ocidental - o egípcio, o grego e o chinês, por exemplo - as palavras desenho e escrita eram expressas da mesma forma. Em chinês, desenho e escrita são representados pelo mesmo ideograma ${ }^{3}$, em grego a palavra GRAPHIKÉ grafada em caixa alta significa desenho e em caixa baixa - graphiké significa escrita. Na língua flamenga, falada em algumas regiões da Bélgica, a palavra "desenho" é teeckning, um empréstimo linguístico do grego techiné, que significa desde o "saber fazer" até a "perfeição formal, arte, ofício, atividade e indústria humana" (GOMES, 1998; CARDEAL, 2009).

$O$ desenho e a escrita foram a maneira encontrada pelo ser humano para expressar suas narrativas e as imagens do espaço, seja em forma verbal ou imagética ou na associação de ambas, o ser humano conta a sua história, por meio de símbolos ou sinais que o represente (CARDEAL, 2009). Para o ser humano, o desenho permanece como um recurso de registro, representando os objetos do mundo. As crianças desenham narrando o seu entendimento sobre as coisas (DUARTE, 2004).

Pesquisas realizadas nos últimos anos como as de Duarte $(2004,2007$, 2008), Duarte e Valente (2005), Valente (2008, 2010), Ventorini (2007, 2012), dentre outras, vêm mostrando que o desenho pode ser utilizado pela criança cega como um recurso para expressar suas imagens mentais.

Diante disso, o desenho foi um dos recursos utilizados durante as coletas de dados em uma pesquisa de mestrado realizada no período de 2015 a $2017^{4}$, para investigar como seis alunos cegos do $7^{\circ}$ ano do Instituto São Rafael ${ }^{5}$ organizavam e representavam o espaço e como esses conhecimentos poderiam ser utilizados para abordar conceitos cartográficos. Os desenhos foram realizados pelos educandos e representavam o trajeto de suas casas até às padarias localizadas no bairro onde

\footnotetext{
${ }^{3}$ Símbolo gráfico utilizado para representar uma palavra.

${ }^{4}$ A referida pesquisa deu origem a dissertação intitulada "O estudo da organização e representação espacial de alunos cegos para o ensino de conceitos cartográficos, que foi defendida no Programa de Pós-Graduação em Geografia da Universidade Federal de São João del-Rei, em fevereiro de 2017.

${ }^{5}$ O Instituto São Rafael está localizado no município de Belo Horizonte, estado de Minas Gerais e exerce a mesma função de uma escola, ele presta apoio pedagógico a alunos que cursam o Ensino Médio em escolas regulares, bem como oferece aulas de orientação e mobilidade, curso musical e oficinas pedagógicas, como datilografia braile e comum, artesanato e atividade da vida diária (VENTORINI, SILVA, FREITAS, 2015).
} 
residiam. O objetivo desse artigo é apresentar a experiência vivenciada com o público-alvo durante a coleta de dados por meio dos desenhos.

$\mathrm{O}$ texto foi organizado em seis seções. Na primeira são apresentadas discussões acerca da importância do desenho como expressão de conceitos representativos para a criança, para isso dialoga-se com autores como Luquet (1969), Arhein (2005), Duarte, (2008, 2009), Almeida (2009), Juliasz e Almeida (2010), dentre outros.

$\mathrm{Na}$ segunda parte discorre-se sobre a importância do desenho para o desenvolvimento cognitivo da criança cega, o diálogo é realizado com Amiralian (1997), Grubtis (2003), Amiralian (1997) Duarte (2004, 2007), Ventorini (2007, 2009, 2012), entre outros.

Durante a terceira seção, o diálogo é realizado com alguns autores da área da Psicologia como Martinez (1989), Huertas, Ochaíta e Espinosa (1993) que discutem a organização espacial das pessoas cegas. No quarta seção é apresentada a metodologia, onde dialoga-se com Lev Vigotsky, que propôs a Perspectiva Sociocultural, em seguida é apresentada a área de estudo, os sujeitos da pesquisada e o procedimento utilizado na coleta de dados.

$\mathrm{Na}$ quarta seção são apresentados os resultados e análises obtidos com a aluna Maria, pois os mesmos sintetizam os dados coletados. Finaliza-se o texto destacando que o desenho pode auxiliar no desenvolvimento cognitivo da criança cega e que é importante trabalhar com locais próximos ao cotidiano dos educandos cegos e partir de situações problemas que os instiguem a refletir sobre as relações espaciais entre os objetos.

\section{O DESENHO COMO EXPRESSÃO DE CONCEITOS REPRESENTATIVOS}

Os desenhos ou grafismos são um tipo de linguagem presente em nossa cultura desde a pré-história. A partir do momento em que compreendemos as representações gráficas, como uma linguagem e como a primeira escrita da criança, podemos afirmar que os desenhos são repletos de elementos referentes ao desenvolvimento cognitivo e motor, cultura e afetividade do indivíduo que o elabora. O desenho é a primeira expressão gráfica, é o começo da representação espacial que antecede o conhecimento da cartografia e seus signos (ALMEIDA, 2009; JULIASZ, ALMEIDA, 2010).

Arhein (2005) faz uma comparação entre os desenhos infantis e os dos povos primitivos, destacando que o ser humano tende a generalizar a forma, independente de sua cultura. Os primeiros desenhos elaborados pelas crianças são linhas retas e círculos, fruto da imitação de um adulto, porém ainda não há na criança a intenção de representar uma figura geométrica. O desenho é simplesmente o resultado do movimento da mão, traçando alguma coisa sobre uma superfície, que não representa necessariamente um objeto e que pode ser nomeado pela criança como "bola", "gato", "papai" etc. Os desenhos infantis não são uma representação do que a criança vê, mas do que ela conhece. O autor afirma que:

A mais antiga - e ainda agora a mais difundida - explicação dos desenhos infantis diz que uma vez que as crianças não representam o que se supõe que elas vejam, alguma atividade mental diferente da percepção deve intervir. É evidente que as crianças se limitam a 
representar as características gerais dos objetos tais como as pernas retas, a cabeça arredondada, o corpo humano simétrico. Estes fatos são amplamente conhecidos; daí a famosa teoria que afirma que "a criança desenha o que conhece ao invés de desenhar o que vê" (ARHEIN, 2005, p. 155).

É importante destacar que o desenho que satisfaz a criança não é o desenho almejado pelos adultos. A criança representa no desenho os objetos que fazem parte de sua vivência, que possuem algum significado para ela, por isso, o desenho infantil é realista (DUARTE, 2009).

Luquet (1969), em sua obra "O desenho infantil", destaca que o desenho da criança não é uma cópia do objeto que ela teve a intenção de desenhar, mas a sua representação, na qual a criança expressa o conhecimento que possui desse objeto, a imagem mental que possui do mesmo. Portanto, a criança desenha o que ela sabe sobre o que vê e não aquilo que ela vê.

Quando uma criança se retrata com um simples círculo e linhas retas, representa-se dessa forma não porque é isso o que vê quando olha para o espelho e não por ser incapaz de produzir um desenho mais fiel, mas porque sua representação preenche as condições que espera encontrar em um desenho. $O$ desenho infantil é uma representação bidimensional na qual a criança transforma conceitos visuais e suas vivências em conceitos representativos, representa suas experiências (ARHEIN, 2005). O autor afirma que:

A criança, na verdade, em seu trabalho, normalmente se baseia em conceitos, mas em conceitos visuais. O conceito visual da mão consiste de uma base arredondada, isto é, a palma, de onde os dedos avançam como pontas retas à maneira de raios de sol, sendo seu número determinado, como veremos, por meio de considerações puramente visuais. A vida mental das crianças é intimamente ligada à sua experiência sensória. Para a mente jovem as coisas são como se parecem, como soam, como se movimentam, como cheiram. [...] a feitura de imagem de qualquer tipo requer o uso de conceitos representativos. Os conceitos representativos proporcionam 0 equivalente, em um meio particular, dos conceitos visuais que se quer representar, e encontram sua manifestação externa no trabalho do lápis, do pincel e do escopro (ARHEIN, 2005, p. 156, 159).

A criança desenha para conhecer o espaço, os esquemas gráficos que realiza, através de repetição e cópia, são representações dos objetos. O desenho infantil evoca os objetos como um esquema geral de uma categoria. Quando alguém mostra para a criança a imagem de um coelho em um livro e diz a palavra coelho, a criança aprende e repete a palavra utilizando não apenas para aquele coelho, mas para todos os coelhos. A criança percebe que a palavra elege uma categoria de objetos. O desenho infantil é um reflexo, no meio gráfico de uma representação mental dos objetos, de uma memória, que resume e categoriza os objetos com os quais a criança convive (DUARTE, 2008).

O desenho, enquanto signo, possui uma função comunicacional e deve ser analisado considerando o contexto em que o mesmo foi produzido. Os aspectos socioculturais influenciam na elaboração do desenho, estando, portanto, o seu resultado gráfico estreitamente ligado à função comunicacional, entre as pessoas e o seu entorno (DARRAS, 2003). 
Duarte (2008) destaca a importância da enunciação da criança durante a elaboração do desenho. A autora relata a vivência com o garoto Gabriel, de seis anos. O menino desenhou uma série de animais, entre eles o elefante, a zebra, o gato e o coelho (figura 1). Durante a elaboração dos desenhos, o menino narrava a sua representação.

Figura 1: Desenhos elaborados por Gabriel

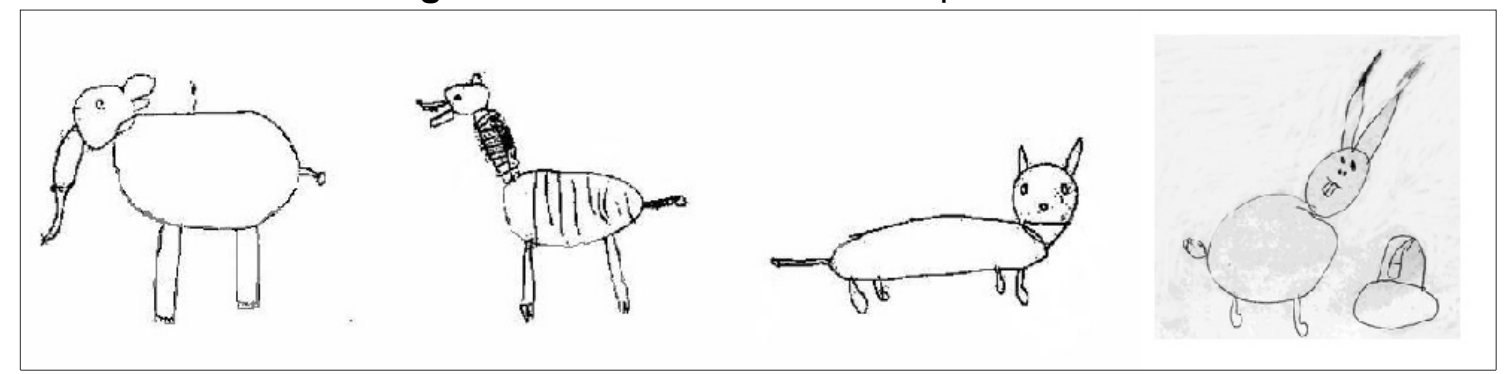

Fonte: DUARTE, 2008, p. 11-12

Enquanto desenhava, Gabriel exercitava, realizava e introjetava uma identificação e um conceito sobre os animais que representava, como se respondesse para si mesmo o que era cada um daqueles animais (DUARTE, 2008). Em uma das narrativas, o garoto destacou:

O coelho é bem fácil. É que nem o elefante. Faz o mesmo, uma barrigona, a cabeça bem pequeninha, menor que a do elefante. Duas orelhonas bem pontudas, olhos bem redondinhos, se quiserem podem pintar os olhos lá no fundo bem de vermelho. Os lábios dele é bem fácil. É só fazer um risquinho pra fazer a boca, depois fazer um quadradinho incompleto com um risquinho no meio. Pra fazer o nariz é bem fácil. É só fazer dois buraquinhos. É só fazer que nem o leão, fazer duas patas. E pra fazer o rabo também é bem facinho. É só fazer uma bolinha bem fofinha. E aí tá pronto o coelho! Viram! Aí é só pintar ele de qualquer cor. Mas vê se não me imita tá? (DUARTE, 2008, p. 12).

Na representação do gato, um animal doméstico, mais disponível ao tato e a visão por diferentes perspectivas, Gabriel desenhou quatro patas. Nos desenhos do elefante, da zebra e do coelho, o garoto representou apenas duas patas, indicando o uso da representação de perfil, possivelmente, o contato que Gabriel possuía com esses animais era por meio de gravuras e de imagens da mídia. Além de ser representado com duas patas, o coelho é desenhado em uma postura ereta, da mesma forma como é comumente utilizado nos livros de história infantil (DUARTE, 2008).

$\mathrm{O}$ ato de desenhar reduz a complexidade do espaço, visto que aproxima objetos distintos, realçando certas equivalências, certas propriedades físicas e/ou biológicas compartilhadas. A construção do desenho auxilia na aquisição de novos conhecimentos e permite que a criança estabeleça laços entre a palavra que nomeia e o desenho que a torna visível (DUARTE, 2008).

O desenho, em cada evolução dos processos intelectuais, perceptivos e motores da criança, representa um compromisso entre suas intenções narrativas e seus meios. É importante considerar as circunstâncias particulares do indivíduo que produziu o desenho, bem como os processos que orientaram sua produção (WALLON et.al, 1990). 
O desenho infantil possibilita uma forte relação entre o desenvolvimento do esquema corporal e a representação da figura humana. As experiências corporais são importantes no espaço, pois são elas que proporcionam a organização espacial interna, que aparece nas representações da figura humana. Essas representações iniciam nas formas fechadas que dão origem à figura-girino para representar um personagem, que, posteriormente, criará uma insatisfação quanto à sua propriedade para representar o corpo, então a criança agrega um corpo à cabeça, correspondendo a separação funcional entre ambos. Conforme o esquema corporal adquire detalhes funcionais, a criança percebe que seu desenho não corresponde plenamente a essa imagem, então agrega detalhes às formas já conquistadas (ALMEIDA, 2009).

Almeida (2009) destaca ainda que existe uma importante relação entre a elaboração da figura da personagem e a representação do espaço, que é a verticalização do corpo. Segundo a autora, a forma vertical do corpo humano e seu deslocamento, a partir de uma postura ortostática (postura ereta), influenciam na apreensão do espaço. A construção do esquema corporal é o ponto de partida para as noções das coordenadas espaciais. A verticalidade do corpo consiste no eixo principal de toda organização espacial, pois o eixo horizontal (frente e atrás) e o vertical (direito e esquerdo) estão presentes na postura corporal. "Portanto, é na infância que a noção das coordenadas espaciais se origina. $O$ desenho de uma personagem não é apenas um desenho, pois trás em si o germe da cartografia" (ALMEIDA, 2009, p. 06).

Os desenhos infantis podem ser utilizados na mediação do ensino do mapa, pois a partir do momento em que a criança percebe que seus rabiscos podem representar objetos e que é ela quem estabelece a relação entre eles, inicia-se um sistema gráfico de representação (ALMEIDA, 2006).

Almeida (2006) ressalta que o desenho da criança não é uma cópia dos objetos, mas um sistema de representação, com uma interpretação real, elaborada pela criança em linguagem gráfica. Os "mapas das crianças" são compostos por elementos do pensamento infantil, através deles, elas representam o seu modo de pensar o espaço, o que persiste mesmo quando entram em contato com conteúdos relativos aos "mapas de adultos" na escola. Para exemplificar as diferenças entre os desenhos infantis ou "mapa das crianças" e o "mapa dos adultos", a autora elaborou o quadro 1 apresentado a seguir:

\section{Quadro 1: Comparação entre o desenho e o mapa}

\begin{tabular}{|l|l|l|}
\hline Localização & $\begin{array}{l}\text { Desenho do espaço } \\
\text { Situa os objetos uns } \\
\text { em relação aos } \\
\text { outros }\end{array}$ & $\begin{array}{l}\text { Mitua os objetos com base nas } \\
\text { coordenadas geográficas (latitude e } \\
\text { longitude). }\end{array}$ \\
\hline $\begin{array}{l}\text { Redução } \\
\text { proporcional }\end{array}$ & $\begin{array}{l}\text { Os objetos são } \\
\text { reduzidos por } \\
\text { comparação: o que é } \\
\text { grande no terreno } \\
\text { parece grande no } \\
\text { desenho, q que é } \\
\text { pequeno também } \\
\text { aparece pequeno no } \\
\text { desenho. }\end{array}$ & $\begin{array}{l}\text { Definida pela escala: todas as } \\
\text { distâncias sofreram a mesma } \\
\text { reduço (nos mapas de grande } \\
\text { escala, pelo menos). }\end{array}$ \\
\hline
\end{tabular}




\begin{tabular}{|c|c|c|}
\hline Projeção & $\begin{array}{l}\text { Há diversas } \\
\text { perspectivas, com } \\
\text { ocorrência rebatidos, } \\
\text { objetos rebs } \\
\text { desdobrados, vistos } \\
\text { a } 95^{\circ} \text { ou a } 45^{\circ} \text {. }\end{array}$ & $\begin{array}{l}\text { Projeção ortogonal dos pontos do } \\
\text { terreno no papel. A superfície da } \\
\text { Terra é projetada sobre o plano } \\
\text { usando-se projeções cartográficas. } \\
\text { As altitudes são projetadas por } \\
\text { meio de curvas de nível. }\end{array}$ \\
\hline & $\begin{array}{lr}\text { Representação } & \\
\text { pictórica, } & \text { com } \\
\text { predomínio } & \text { de } \\
\text { equivalentes } & \\
\text { analógicos. } & \end{array}$ & $\begin{array}{l}\text { Uso de convenções ou da } \\
\text { semiologia gráfica. }\end{array}$ \\
\hline
\end{tabular}

Fonte: ALMEIDA, 2006, p. 100

A aquisição de equivalentes (símbolos) no desenho do espaço é extensa e envolve, principalmente, a construção da perspectiva, da distância e da proporção (relações espaciais projetivas e euclidianas); a partir dessas aquisições que se pode pensar o ensino/aprendizagem de conceitos cartográficos. Assim sendo, é importante considerar os conhecimentos espaciais da criança antes de prosseguir em propostas para o ensino de mapas (ALMEIDA, 2006).

Como já detacados, autores como Luquet (1969), Darras (2003), Arhein (2005), Almeida (2006, 2009), Duarte (2008), dentre outros, ressaltam a importância do desenho como forma de representação para as crianças que enxergam. Mas e as crianças que não enxergam, o desenho pode ser utilizado por elas para representar suas imagens mentais?

Amiralian (1997) ressalta que as atividades de desenhos com alunos cegos ainda são pouco exploradas. Frequentemente são levantadas questões sobre a utilização do desenho com as pessoas com deficiência visual. Muitos o consideram uma atividade imposta pelos normovisuais. À medida que solicitamos aos alunos cegos que reproduzam desenhos feitos dentro dos padrões visuais, automaticamente exigimos a conformação de processos visuais, e consequentemente ignoramos sua diferença básica. Porém, se considerarmos sua expressão gráfica como função de sua expressão motora, ela poderá se constituir como uma possibilidade para expressar suas imagens mentais. A seguir, é apresentada uma discussão acerca da importância do desenho para o desenvolvimento cognitivo das crianças cegas.

\section{A IMPORTÂNCIA DO DESENHO PARA A CRIANÇA CEGA}

Antes de iniciar uma discussão sobre a importância do desenho para o desenvolvimento cognitivo da criança cega, é importante destacar que a criança não se preocupa com a aparência visual do desenho, mas com o significado que o mesmo possui (GRUBTIS, 2003).

O referencial teórico que discute sobre atividades de desenhos com alunos cegos ainda é escasso, porém a preocupação com a temática é antiga. Amiralian (1997) ressalta as pesquisas de Lowenfeld (1939), que investigou a natureza da atividade criativa através de desenhos e expressões plásticas de pessoas com deficiência visual. Para isso, utilizou estudos de psicólogos alemães que usaram desenhos de alunos cegos para analisar o desenvolvimento da criatividade, de conceitos de forma e espaço e de representações mentais. $O$ autor destaca que a 
ausência da visão não é um impedimento para a representação plana e espacial dos objetos, e que existem duas condições essenciais para desenhar: a capacidade do indivíduo de se orientar no plano do desenho e o desenvolvimento da criatividade, relacionada com a capacidade de projetar algo de si.

Lowenfeld (1939) concluiu que: a) as pessoas cegas conseguem expressar unidades em seus desenhos, por meio de uma síntese construtiva de impressões parciais; b) a concepção do trabalho como um todo está presente, a priori, somente quando é dominada por uma determinação subjetiva da experiência; c) quando experiências autoplásticas tornam-se a base do trabalho criativo, o tamanho e as proporções relativas dos objetos são determinados pelo julgamento de valor e pela significação emocional para o artista; d) pessoas cegas e de baixa visão traduzem ritmos de movimento e som para formas rítmicas. Em outras palavras, em suas composições, espaço e tempo são fundidos dentro de uma mesma unidade (AMIRALIAN, 1997).

Entre os pesquisadores que abordam o tema desenhos de alunos cegos, como Duarte (2004, 2007, 2008), Duarte e Valente (2005), Valente (2008, 2010), Ventorini (2007, 2009, 2012, 2014), Juliasz (2012), Morais (2009) etc., destaca-se neste artigo os estudos de Maria Lúcia Batezat Duarte e Silvia Elena Ventorini. Apesar do público-alvo da pesquisa relatada no presente artigo estar inserido em um contexto diferente - o Instituto São Rafael, localizado no município de Belo Horizonte (MG) - as publicações de Duarte $(2004,2007,2008)$ foram importantes para entender a formação da imagem mental e da aquisição da linguagem gráfica de crianças cegas; e as de Ventorini $(2007,2009,2012,2014)$ foram importantes na compreensão de como as pessoas cegas representam suas imagens mentais através de desenhos, da importância da enunciação após a elaboração das representações e da utilização da análise não comparativa de resultados.

Destaca-se que a investigação não teve como intuito ensinar as crianças do Instituto São Rafael a desenhar, mas utilizar esse recurso para investigar como eles representam suas imagens mentais. Além disso, buscou-se coletar dados que possibilitassem compreender não apenas a representação no desenho, mas também sua enunciação.

Duarte $(2004,2007)$ relata a experiência vivenciada com Manuella, que no ano de 2002 possuía 08 anos de idade e que ficou cega aos 03 anos de idade. Como Manuella era uma menina tímida, a pesquisadora iniciou a narração de histórias para introduzir os desenhos que queria mediar, além disso, elaborava representações dos objetos na tridimensionalidade (maquetes) para que a menina pudesse tatear. As bordas da superfície das maquetes eram percebidas como "linhas de contorno" e associadas às figuras geométricas. Assim como os normovisuais, os alunos cegos compreendem a noção de linha de contorno, que é a linha imaginária que as margens dos objetos permitem intuir (KENNEDY, 1983).

O trabalho de memorização com uma criança cega é mais demorado que com uma criança que enxerga, pois a criança que enxerga imita os movimentos de um adulto ao escrever; já as crianças cegas são impossibilitadas de observar e, por isso, não os imitam, se não houver uma mediação com essa finalidade (VENTORINI, 2012). Durante as atividades com Manuella, Duarte (2007) percebeu que estava realizando dois processos de ensino e aprendizagem paralelos:

No primeiro, por meio da percepção tátil, Manuella conhecia os objetos em versões simplificadas, esquemáticas, facilitadoras em relação ao tipo de percepção utilizada. Neste processo, e por meio 
de etapas, evoluindo da configuração tridimensional à configuração bidimensional, Manuella estava adquirindo uma concepção de desenho que requeria a planificação do objeto e a sua tradução em linhas de contorno. Mas, no segundo processo, no qual o desenho linear deveria ser realizado e repetido, percebi que, para além da memória tátil da configuração do desenho, parecia atuar com ênfase a memória motora de uma sequência gráfica necessária. Esta percepção foi possível devido algumas pistas importantes: 1) A manutenção de uma mesma sequência de traçado da figura era essencial. Se por engano, ao iniciar o traçado, havia alguma alteração na condução do exercício, esse fato acarretava claramente um desconserto e, não raro, um impedimento à conclusão da tarefa; 2) Manuella demonstrava prazer e atenção quando, com sua mão sobre a minha mão, podia perceber a ação de desenhar, isto é, o movimento motor sequencial que realizava o desenho DUARTE, 2007, p. 03).

Após reconhecer e desenhar esquemas gráficos básicos, como sol, árvore, casa etc., Manuella adquiriu autonomia para elaborar representações gráficas de objetos do seu cotidiano. Ao elaborar seus desenhos, Manuella representava-se como personagem central e utilizava-se de seu corpo como primeira referência no espaço. Os desenhos mostraram que Manuella possuía uma concepção de espaço, apesar de não visualizar as relações de distância e proximidade entre os objetos (DUARTE, 2007).

Ventorini (2012) relata a vivência nas Escolas Municipais Integradas de Educação Especial "Maria Aparecida Muniz Michelin - José Benedito Carneiro Deficientes Auditivos e Deficientes Visuais - DA/DV", localizadas no município de Araras - SP e apresenta os dados coletados com alunos cegos desta Instituição através de desenhos. A pesquisadora tinha como objetivo utilizar o desenho para investigar como os alunos expressavam seus conhecimentos e organizações espaciais de locais vividos por meio das representações. A autora relata uma série de atividades desenvolvidas com três alunos cegos (Léo, João e Laura), dentre elas, os dados coletados por meio de desenhos. Entre os desenhos elaborados pelos alunos, destacamos os da sala de aula.

Para a elaboração do desenho, o aluno Léo adotou como ponto de referência inicial uma determinada parede e desenhou as carteiras no mesmo plano do chão (vista de cima); já os quadros de cartazes e a lousa foram desenhados rebatidos sobre o plano do chão (VENTORINI, 2012).

Ao contrário de Léo, João solicitou um ponto de referência para iniciar o desenho, a pesquisadora indicou a lousa como referência inicial. O aluno não apresentou dificuldades na elaboração do desenho e representou a maioria dos objetos do ponto de vista vertical, assim como adotou o limite da folha como limite de área (VENTORINI, 2012). A figura 2 ilustra os desenhos dos alunos. 
Figura 2: Desenhos elaborados por Léo e João

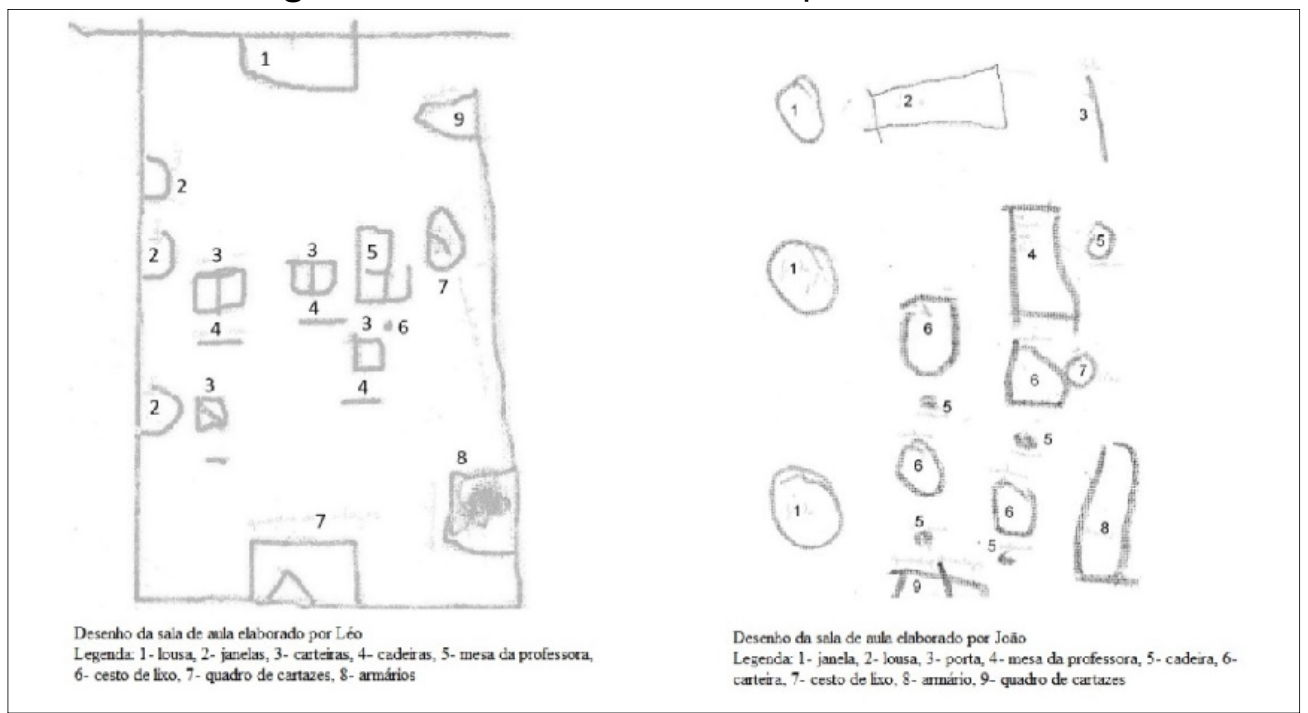

Fonte: VENTORINI, 2012, p. 90, 106

Já a aluna Laura, assim como João, solicitou um ponto de referência inicial; a pesquisadora novamente indicou a lousa como referência. A educanda representou os objetos na perspectiva vertical e também utilizou como limite de área o limite da folha; objetos como a porta, lousa, quadro de cartazes e janelas parecem ser representados dissociados das paredes. Laura representou os objetos harmoniosamente, respeitando a relação de tamanho (proporção), as formas e as distâncias entre os objetos. A aluna possuía pouca sensibilidade tátil e dificuldade motora, o que pode ter impedido a representação da forma dos objetos com maior coerência com a realidade, mas a forma perdeu seu valor diante dos valores culturais e sociais atribuídos ao desenho (VENTORINI, 2012).

Ventorini (2012) traz um referencial teórico para a análise dos dados que permite a conclusão de que as pessoas cegas formam imagens mentais obtidas através de informações no deslocamento das mãos nas direções verticais e horizontais, ou seja, por meio do eixo de simetria no qual utilizam como referência a vertical do próprio corpo. Além disso, a autora destaca que os indivíduos cegos representam objetos com os quais possui significativa vivência e, por isso, é importante ouvir outrem para entender suas representações. A autora destaca que investigar a maneira como o outro representa e organiza o espaço significa investigar as suas relações sociais e culturais.

As representações gráficas não expressam apenas uma vida pessoal, mas um contexto social na qual a criança está inserida. O desenho deve ser analisado como um todo, não se deve isolar algum objeto e atribui-lo algum valor específico. $O$ signo não possui seu significado, senão nas suas relações com a interligação de tudo aquilo a que ele pertence. A criança desenha e, muitas vezes, nomeia os seus traços, simultaneamente. Ao planejar seu desenho, ela ordena suas ações através da fala (SILVA, 1998; GRUBTIS, 2003).

A fala organiza a representação gráfica. Quando uma criança diz que vai desenhar uma casinha e dirige a sua ação gráfica a isso, está sendo orientada pela palavra. Ao mesmo tempo em que o desenho organiza a fala, como acontece quando determinada marca gráfica sugere um rio e a criança denomina seu traçado estimulada pelo grafismo (SILVA, 1998). 
Vigotsky $(1989,1991)$ destaca que a palavra é o principal veículo de mediação na relação do indivíduo com o outro e consigo mesmo, através das funções de orientar o comportamento. A enunciação egocêntrica na criança está associada às suas atividades práticas, como desenhar, brincar etc. A função intelectual da linguagem está interligada com as ações do indivíduo, por assinalar e refletir os mais importantes momentos da operação intelectual prática, pois orienta a ação da criança, subordinando essa ação a uma intenção. A linguagem egocêntrica, além de função expressiva, é um meio de pensamento, pois possui a função de solucionar alguma tarefa que surja no comportamento.

Como exemplo, Vigotsky (1991) destaca que ao desenhar um bonde, uma criança forçou o lápis e o quebrou enquanto desenhava uma das rodas, em seguida pronunciou em voz baixa, como se falasse sozinha: "Ele está quebrado", então continuou o seu desenho com tintas e representou um vagão quebrado que estava sendo consertado depois de um acidente. Enquanto representava graficamente o vagão quebrado, a criança pronunciava para si mesmo o motivo da mudança do tema do seu desenho.

Durante a trajetória no Instituto São Rafael, observamos o quanto as relações sociais estão presentes nas representações dos indivíduos e a importância de ouvilos para compreendê-las. Destaca-se que, para compreender como os alunos cegos representam o espaço através dos desenhos, primeiramente é preciso entender como eles se organizam nele. Por isso, a seguir, discorre-se sobre a organização espacial das pessoas cegas.

\section{ORGANIZAÇÃO ESPACIAL DAS PESSOAS CEGAS}

A discussão é iniciada com um trecho do livro $A$ história da minha vida, onde Hellen Keller, que ficou cega e surda aos 18 meses de vida relata sua história. Neste trecho, a autora destaca:

Mesmo antes da chegada de minha professora, eu costumava tatear ao longo das quadradas e rígidas cercas de buxo e, guiada pelo olfato, encontrava as primeiras violetas e lírios. Lá também, depois de um acesso temperamental, eu ia buscar conforto e esconder meu rosto quente na relva e nas folhas frescas. Que alegria era me perder naquele jardim de flores, perambular feliz de um local para outro até que, esbarrando subitamente numa bela videira, eu a reconhecesse por suas folhas e flores e soubesse que era a videira cobrindo a dilapidada casa de verão na extremidade do jardim! [...] Mas as rosas eram as mais adoráveis de todas. [...] Pendiam em compridas guirlandas de nossa varanda, enchendo todo 0 ar com sua fragrância, sem serem afetadas por nenhum outro cheiro (KELLER, 2008, p. 13).

Este relato ilustra como os sentidos podem ser utilizados pela pessoa cega para se deslocar e se orientar no espaço. O indivíduo cego percebe, explora e organiza os objetos no espaço através de todos os seus sentidos - audição, olfato, paladar e tato (VENTORINI, 2007). O sentido do tato se subdivide em quatro, sendo o sistema somatossensorial, que permite a identificação de texturas; a propriocepção ou cinestesia que possibilita reconhecer a localização do corpo; a termocepção que possibilita a percepção da temperatura e a nocicepção que é a percepção da dor (GUYTON, 1996). Os sentidos do tato, olfato, audição e paladar, 
juntamente com os processos psíquicos superiores e as relações sociais que o sujeito cego possui com um determinado espaço, possibilitam o seu deslocamento e a organização dos objetos nesse espaço.

Quando se trata da organização espacial de pessoas cegas, devemos considerar dois tipos de organização: a de rotas e a configuracional. A organização de rotas possui caráter estático e sequencial: nesta configuração é estabelecido um ponto de partida (ex: casa do aluno) e outro de chegada (ex: padaria); além disso, são estipulados os objetos entre esses dois pontos (ex: calçadas, casa do vizinho). Enquanto a organização configuracional, possui caráter dinâmico e coordenado, os objetos são organizados dentro de um espaço, como um bairro ou uma cidade, neste caso, não há um ponto de partida e um de chegada. Nessa organização considera-se a representação integrada dos objetos de um determinado espaço, levando em conta suas relações e localizações. Além disso, a organização espacial depende ainda da interação completa entre as características dos objetos e espaço, como tamanho, distância, forma, entre outros, bem como da relação do indivíduo com o lugar (emoções, relações sociais, vivências, grau de importância etc.) (MARTINEZ, 1989; HUERTAS, OCHAÍTA, ESPINOSA, 1993).

Nas representações de distância entre os objetos, as pessoas cegas consideram o espaço-tempo. A distância percorrida é calculada, os obstáculos existentes entre o caminho que o torna mais longo e demorado, como desnível do terreno, quebra-molas, curvas etc. são considerados (VENTORINI, 2012). Além disso, a organização espacial possui informações atributivas que se referem às relações particulares que a pessoa possui e que são expressas nas representações. Porém, essas mesmas representações possuem atributos comuns a todos, como distância e características físicas dos objetos (HUERTAS, OCHAÍTA; ESPINOSA, 1993).

Na organização espacial são consideradas dois tipos de distância: euclidiana e funcional. A distância funcional corresponde à real, aquela efetivamente percorrida para chegar de um ponto a outro, ela envolve o deslocamento do corpo e os desvios mínimos entre os obstáculos. A distância euclidiana corresponde à menor distância entre dois pontos, desconsiderando os desvios e obstáculos entre eles (VENTORINI, 2007, 2009).

Essas questões foram observadas no Instituto São Rafael. Durante a coleta de dados observou-se o quanto a mobilidade dos alunos cegos se difere de uma pessoa normovisual e como as experiências vivenciadas com o local são importantes para a formação de imagens mentais. Como exemplo, compartilha-se uma situação vivenciada dentro do Instituto com uma das autoras deste artigo. Em uma das visitas técnicas ao Instituto São Rafael, a pesquisadora estava à procura da professora de Geografia que havia mudado de sala, por não conhecer toda a área do Instituto São Rafael, e pela semelhança visual entre os corredores e rampas, ela se perdeu dentro da Instituição.

Em uma das rampas a pesquisadora se encontrou com dois alunos cegos que a perguntaram se estava perdida e se precisava de ajuda. Ao mencionar que estava à procura da nova sala da professora de Geografia, eles se prontificaram a conduzila até o local. Durante o trajeto, um dos alunos perguntou à mesma sobre a sensação de ser guiada por uma pessoa cega. A pesquisadora ficou surpresa com o questionamento e por não saber o que responder, logo, os questionou sobre como eles não se perdiam dentro da Instituição, visto que as rampas e corredores eram muito parecidos visualmente. Os educandos ressaltaram que as rampas e 
corredores não eram parecidos, pois alguns possuíam uma declividade maior em relação a outros.

As pessoas cegas se deslocam com mais dificuldades que os normovisuais, pois é o canal visual que possibilita antecipar os obstáculos, como postes, árvores, telefones públicos, entre outros; por isso, as pessoas cegas devem prestar mais atenção ao trajeto que os normovisuais. A utilização da bengala nem sempre permite a antecipação de um obstáculo pelo indivíduo cego; por isso, o mesmo pode colidir com as partes superiores dos objetos antes de tocar suas partes inferiores com a bengala. O material cartográfico tátil pode auxiliar na amenização dessas dificuldades, porém, é necessário investigar como as pessoas cegas adquirem informações através dos mapas táteis e como as utilizam em seu cotidiano (VENTORINI, 2012).

Warren (1994) relatou diversas pesquisas na área de aquisição de conceitos relativos ao espaço com crianças cegas congênitas, onde os resultados foram positivos, como a pesquisa realizada por Landau et al $(1981,1984,1986)$ com uma criança cega congênita, que obteve resultados excelentes em provas nas quais deveria locomover-se até pontos previamente a ela mostrados (LEME, 2003).

Warren (1994) ressalta que algum resíduo visual ou experiência de já ter enxergado auxiliam muito a criança na constituição de noção do espaço, mas, por outro lado, há, como mostra a pesquisa de Landau et al (1981, 1984, 1986), crianças congenitamente cegas que possuem ótimo desempenho. Então, não se pode afirmar que a cegueira congênita determina prejuízo, mas devemos compreender quais processos ocorrem nos casos bem sucedidos e o que estaria impedindo o bom desempenho dos outros casos (LEME, 2003).

Pesquisas têm mostrado que a pessoa com cegueira congênita e com pouca memória visual tem dificuldades em estimar distâncias euclidianas, pois é o canal visual que permite a estimativa da distância entre dois pontos, porém não apresentam dificuldades consideráveis para a distância funcional. A partir da adolescência, alguns indivíduos possuem maturidade e conhecimento para representar espaços integrados, respeitando a distância funcional entre os objetos (HUERTAS, OCHAITA, ESPINOSA, 1993).

Ao atingir a adolescência, a pessoa com deficiência visual terá maturidade para elaborar esquemas mentais precisos; todavia, a qualidade desses esquemas dependerá das experiências vividas, orientação e mobilidade etc. (HUERTAS, OCHAÍTA, ESPINOSA, 1993). Com base nessas informações, solicitou-se que o público-alvo representasse sua imagem mental. Ressalta-se que:

O termo representação é usado considerando que cada indivíduo tem suas próprias percepções e modos de organizar suas representações sobre o espaço geográfico e não deve ser entendido ou analisado a partir de regras e conceitos da ciência cartográfica, sendo que os produtos dessa ciência devem proporcionar ao indivíduo informações que possibilitem adquirir conhecimentos novos sobre o espaço em que vive e atua (VENTORINI, 2009, p. 52).

Tendo como base o diálogo com os autores que discutem a temática desenhos de crianças cegas, pautou-se na convicção de que as representações do espaço por pessoas cegas trazem marcas de suas vivências cotidianas e que cada individuo representa o que é significativo para si. A partir da vivência no Instituto São Rafael, contatou-se por meio de diálogos com os alunos cegos que eles seriam capazes de representar o trajeto percorrido de suas casas até à padaria do bairro 
em que residiam. Iniciou-se então, a coleta de dados por meio de desenhos, conforme os procedimentos metodológicos, na sequência, apresentados.

\section{ELABORAÇÃO DOS DESENHOS: PROCEDIMENTOS METODOLÓGICOS}

O procedimento teórico-metodológico teve como base a Perspectiva Sociocultural, que foi proposta Lev Semenovitch Vigotsky e permite considerar que a formação do indivíduo ocorre por meio de sua interação com o ambiente e relação com as pessoas, ou seja, com a cultura e sociedade que convive. O autor afirma que os processos psíquicos superiores não estão presentes desde o nascimento do indivíduo, mas se originam em suas relações sociais e culturais. O indivíduo não é um ser passivo que reage às pressões do meio, mas um indivíduo que realiza uma atividade organizadora, na sua interação com o mundo, capaz, inclusive de renovar a sua própria cultura (VIGOTSKY, 1983; COELHO, PISONI, 2012).

A compreensão do ser humano está relacionada com o processo de internalização das formas culturalmente dadas de funcionamento psicológico. O ser humano nasce apenas com as funções psicológicas elementares que se transformam em funções psicológicas superiores, que são responsáveis pelo controle consciente do comportamento e se dão por meio das interações socioculturais (VIGOTSKY, 1983, REGO, 1995).

As interações do indivíduo com o meio são construídas a partir da sua inserção em um contexto sociocultural que é formado pela família, pela escola, pelo bairro etc. Essas interações são processos interpessoais (entre pessoas), que se transformam em processos intrapessoais (no interior da pessoa). As funções no desenvolvimento da criança aparecem, primeiramente, no nível social, e, depois, no nível individual. Isso se aplica igualmente para a memória lógica, a atenção voluntária e para a formação de conceitos (VIGOTSKY, 1983).

Quanto à formação de conceitos, Vigotsky $(1983,1991,2001)$ ressalta que existem os conceitos espontâneos e os conceitos científicos. Os conceitos espontâneos são desenvolvidos naturalmente pela criança cega através das suas experiências cotidianas. São construídos fora do contexto escolar é a percepção que o indivíduo possui sobre o seu mundo, ou seja, suas próprias representações. O conceito científico é aquele produzido no contexto escolar por meio da mediação do professor, com abstrações formais dos conceitos espontâneos.

Os limites entre os conceitos científicos e espontâneos são extremamente fluidos. O desenvolvimento do conceito científico é apoiado em um nível de maturação do conceito espontâneo esses conceitos não estão separados, mas em um contínuo processo interativo (SCHROEDER, 2007).

Vigotsky (1997) ressalta ainda que a educação do aluno com deficiência visual deve ser a mesma de um aluno normovisual, desde que a deficiência seja respeitada e não seja vista como um empecilho para a aprendizagem. As considerações de Vigotsky (1997) sobre o desenvolvimento das crianças cegas e dos processos de compensação são importantes para a compreensão das relações sociais presentes nas representações dos alunos cegos do Instituto São Rafael.

A área de estudo foi o Instituto São Rafael, localizado em Belo Horizonte (MG), e o público-alvo foi composto por seis alunos cegos do $7^{\circ}$ ano do Instituto São Rafael. Como apresentado no Quadro 2, participaram do estudo três pessoas do sexo masculino e três do sexo feminino, com idades entre 11 e 13 anos. Com o 
intuito de preservar a identidade dos alunos participantes da pesquisa, nomes fictícios foram utilizados.

Quadro 2: Características do Público-alvo

\begin{tabular}{|c|c|c|c|c|c|}
\hline \multicolumn{7}{|c|}{ Características do Público - Alvo } \\
\hline $\begin{array}{c}\text { Nome } \\
\text { Fictício }\end{array}$ & Sexo & $\begin{array}{c}\text { Idade que } \\
\text { adquiriu a } \\
\text { deficiência }\end{array}$ & $\begin{array}{c}\text { Idade em } \\
\text { que } \\
\text { participa da } \\
\text { pesquisa }\end{array}$ & $\begin{array}{c}\text { Nível Escolar em } \\
\text { que adquiriu a } \\
\text { deficiência }\end{array}$ & Alfabetização \\
\hline Tiago & M & Nascença & 11 & - & Braille \\
\hline Sônia & $\mathrm{F}$ & 5 anos & 12 & Pré-Escolar & Braille \\
\hline Maria & $\mathrm{F}$ & Nascença & 12 & - & Braille \\
\hline Brenda & $\mathrm{F}$ & 7 anos & 13 & Pré-Escolar & Braille \\
\hline Juliano & $\mathrm{M}$ & 2 anos & 13 & Maternal & Braille \\
\hline Caio & $\mathrm{M}$ & 2 anos & 12 & Maternal & \\
\hline
\end{tabular}

Siglas: F - Feminino/ M - Masculino.

Fonte: Elaborado pela autora

O procedimento foi realizado com cada aluno individualmente. Como material de apoio foram utilizadas uma folha A4 e uma caneta 0.7 milímetros, além disso, foi utilizado um celular para gravar o diálogo dos alunos com a pesquisadora durante o processo. Enquanto elaboravam as representações do trajeto de suas residências até à padaria, os alunos expressavam por meio da palavra o que cada símbolo representava, quais pontos de referência utilizavam nesse trajeto e quais as relações sociais vivenciadas no local representado. Após elaborarem os desenhos, foi solicitado que os alunos expressassem por meio da palavra em qual endereço residiam com o intuito de localizar por meio do Google a localização de suas residências e padarias e verificar a similaridade do desenho com o trajeto real. Ressalta-se que todos os sujeitos da pesquisa representaram o trajeto de suas casas até às padarias por meio de desenhos.

Para analisar os dados, foi utilizada a Perspectiva Sociocultural, por isso, cada detalhe da enunciação do desenho é de suma importância para a compreensão do mesmo. Para Vigotsky (1989) a relação entre pensamento e palavra é um processo, um movimento contínuo e é a partir das palavras que o pensamento passa a existir. A partir da enunciação da imagem mental representada no desenho, é possível expressar o pensamento acerca do local representado. Não se considera viável apresentar neste artigo os resultados e análises obtidos com cada sujeito participante. Tal opção se justifica pela importância de ser fiel à riqueza dos detalhes da enunciação do desenho, assim como pelo fato de a experiência de investigação com a aluna Maria representar resultados e análises obtidos com os seis educandos. 


\section{OS DESENHOS DE ALUNOS CEgOS: RESULTADOS, ANÁLISES E POSSIBILIDADES}

Antes de apresentar os resultados e as análises dos desenhos, julga-se importante ressaltar que, o desenho infantil não é uma cópia do objeto que a criança teve a intenção de desenhar, mas a sua representação, na qual expressa a imagem mental que possui sobre o objeto. A criança normovisual desenha o que ela sabe sobre o que vê e não o que ela vê (LUQUET, 1969) e as crianças cegas desenham o que percebem e sentem e não o que os normovisuais veem, desenham o que consideram importante. Nesse caso, as formas do desenho não são relevantes, o que importa são os significados das representações e sua coerência com o ambiente real.

Durante a elaboração do desenho do trajeto de suas casas até às padarias, todos os alunos utilizaram a mão direita para empunhar a caneta e a mão esquerda para acompanhar o traçado, usando a coordenação bimanual, onde cada mão possui uma função assimétrica, sendo que uma delas é dominante e a outra atua como auxiliar (RUBAYO, et.al, 2007).

Cada sujeito representou objetos que possuíam significativa importância para si e utilizaram suas casas como ponto de referência inicial para a elaboração do trajeto. Os alunos representaram trajetos que variavam de 200 a 400 metros em uma folha $A 4$, utilizando os conceitos de redução proporcional, relação de vizinhança, localização e de simbologia.

Durante a enunciação dos desenhos, os alunos destacaram que utilizavam os barulhos, cheiros, subidas, descidas, curvas, direções de direita e esquerda, degraus, quebra-molas (lombadas), texturas dos calçamentos e distância percorrida para obter informações durante o trajeto, indicando utilizar os sentidos da audição, do olfato e do tato (o sistema somatossensorial que permite a identificação de texturas e a propriocepção ou cinestesia que possibilita reconhecer a localização do corpo); a distância funcional e o esquema corporal, juntamente com os processos psíquicos superiores.

Apesar dos sujeitos utilizarem procedimentos comuns a todos, seus desenhos eram carregados de informações atributivas, que se referem às relações particulares que os indivíduos possuem com o local representado (HUERTAS, OCHAÍTA, ESPINOSA, 1993). Para exemplificar os dados coletados, apresenta-se a experiência com a educanda Maria.

A distância da casa de Maria até à Padaria era de aproximadamente 300 metros, ao representar esse trajeto em uma folha A4, a educanda utilizou o conceito de redução. Enquanto desenhava, Maria explicava, por meio da palavra, sua representação, e narrava o que cada símbolo utilizado no desenho representava, utilizando o conceito de simbologia e de legenda narrada. Ventorini (2012) ressalta que o conceito de legenda escrita pode ser mediado a partir da legenda narrada. A criança desenha e geralmente nomeia os seus traços simultaneamente. Quando planeja o seu desenho, ela ordena suas ações através da palavra (SILVA, 1998; GRUBTIS, 2003). Tal ordenação pode ser realizada também pela escrita, assim, inicia-se o conceito de legenda escrita.

Ao elaborar seu desenho, Maria representou Sua Casa e a utilizou como ponto de referência inicial na representação do trajeto, em seguida representou a Rua. Apesar de a Rua possuir vários objetos, a educanda representou apenas os que possuíam significativa importância para ela, como a Casa da Tia, onde brincava 
com a prima, a Casa do Tio, onde morava a sua madrinha, a Casa da Avó, aonde a educanda ia quase todos os dias visitar os avós, a Loja do Padrasto, onde buscava frutas e verduras com a sua mãe e, por último, a Padaria. A figura 3 ilustra o desenho elaborado pela aluna e a figura 4 ilustra o trajeto da Casa da Maria até à Padaria.

Figura 3: Desenho do trajeto de Casa à Padaria elaborado por Maria

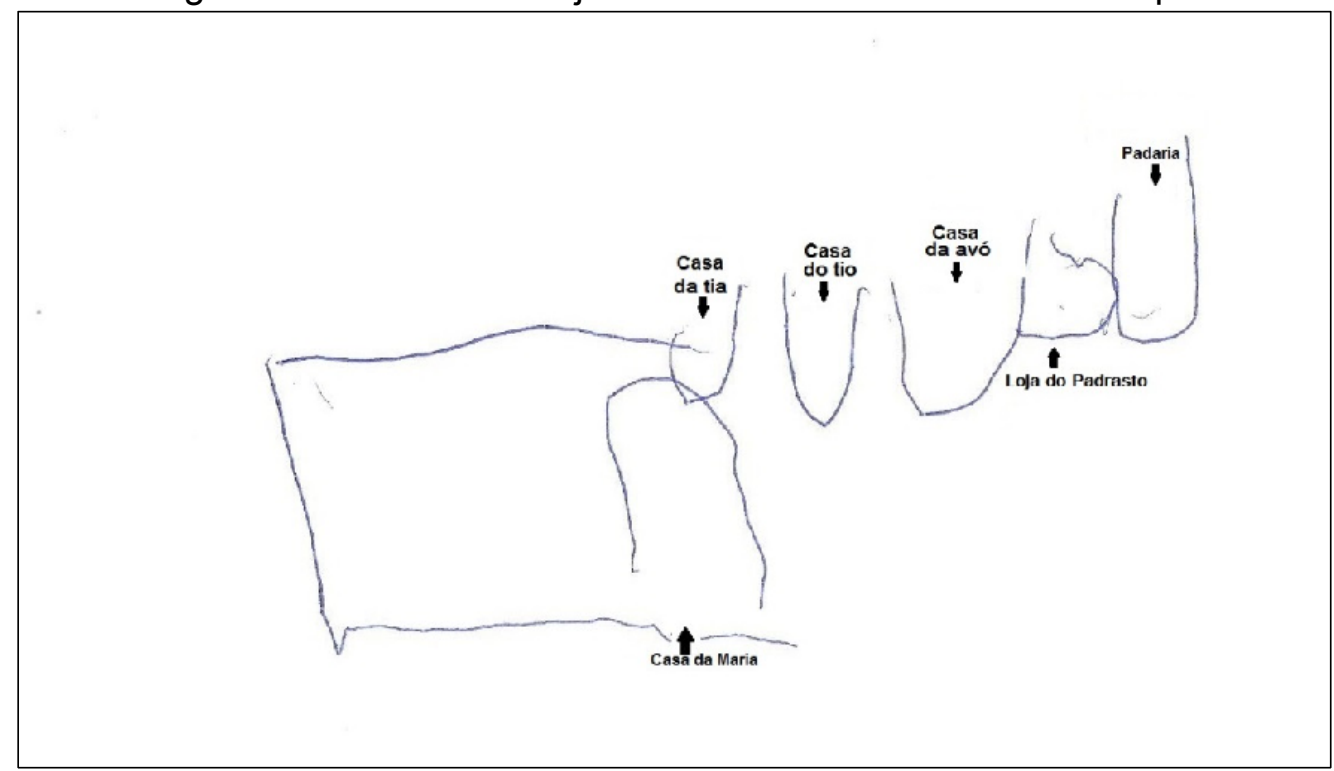

Fonte: Acervo das autoras

Figura 4: Trajeto da casa da Maria até à Padaria

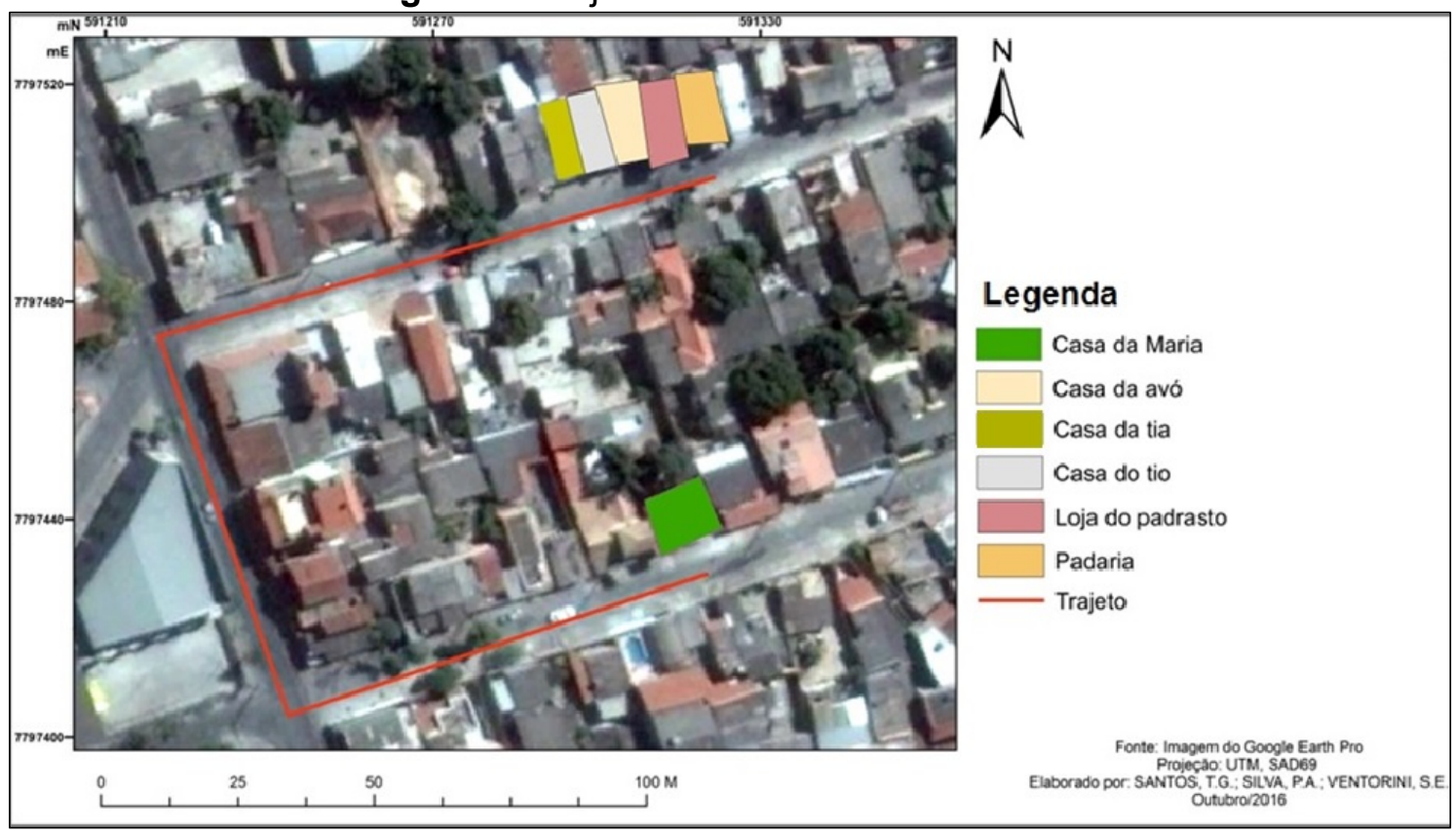

Fonte: Acervo das autoras

No desenho elaborado por Maria, os objetos foram situados uns em relação aos outros e reduzidos proporcionalmente (com exceção de Sua Casa). A educanda utilizou os conceitos de localização e redução proporcional. A educanda representou Sua Casa maior em relação às outras e, durante a narrativa, explicou que a 
representou naquelas dimensões, pois era a Sua Casa, evocando o último ego e revelando suas modalidades de pertencimento ao mundo (GRUBTIS, 2003).

Cada uma de nossas casas possui suas fragrâncias, corredores e portas secretas, espaços, recantos, alquimia, culinária, ruídos e silêncios, fogos e águas, luzes, penumbras assustadoras ou propícias aos desabafos. A imagem da casa, alegre ou não, nos acompanha ao longo de nossa vida. Esse arquétipo ligado a nossa segurança, amores, posses, status social, está inscrito mais profundamente em nós, até na nossa parte primitiva e animal, como a concha para o caracol (GRUBTIS, 2003, p.100).

Durante a elaboração do desenho, Maria destacou que Sua Casa estava localizada na rua de trás da Padaria. Sendo assim, a educanda andava aproximadamente 100 metros, virava à direita e subia aproximadamente a mesma distância percorrida anteriormente. Em seguida, virava à direita, passava em frente à Casa da Tia, onde brincava quase todos os dias com sua prima e que era reconhecida pelo latido do cachorro e pela distância percorrida; em frente à Casa do Tio, que estava localizada ao lado da Casa da Tia e onde morava a sua madrinha; em frente à Casa da Avó, aonde a educanda ia quase todos os dias e que era reconhecida pela calçada, que possuía uma textura diferente das outras calçadas, pois era construída de piso antiderrapante; em frente à Loja do Padrasto, onde buscava frutas e verduras com a sua mãe e que era reconhecida pelo cheiro das frutas, em especial pelo aroma do abacaxi que, segundo a educanda, era o que mais se destacava entre os demais. Após passar por esses pontos de referência, Maria chegava à Padaria, que era reconhecida pelo cheiro do pão e pela conversa dos clientes e funcionários.

Ao utilizar as direções (direita-esquerda), Maria usou o esquema corporal em seu trajeto; ao destacar a subida, a educanda utilizou o sentido da propriocepção (tato); ao ressaltar o latido do cachorro, o cheiro das frutas e pães e a conversa dos funcionários e clientes, Maria utilizou os sentidos do olfato e audição; além disso, a educanda usou o espaço-tempo e a distância funcional, juntamente com os processos psíquicos superiores.

Ao situar os objetos uns em relação aos outros, Maria utiliza o conceito de localização, ao reduzi-los comparando com os seus tamanhos reais (o que é grande no real, é representado grande no desenho, o que é pequeno, aparece pequeno), a educanda utiliza o conceito de redução proporcional. Como ressaltado por Almeida (2006) esses conceitos podem ser utilizados para mediar o ensino do mapa.

A elaboração do desenho remeteu à educanda lembranças de relações sociais vivenciadas em seu cotidiano, como a brincadeira com a prima, a visita aos avós, as compras com a mãe. Maria representou, em seu desenho, objetos que faziam parte do seu contexto sociocultural. Como destacado por Duarte (2009), a criança desenha os objetos que fazem parte de sua vivência e que possuem significado para ela.

O ensino de conceitos básicos de cartografia é facilitado, se for mediado a partir desses referenciais cotidianos dos educandos. Tais colocações já são fundamentadas no ensino de cartografia para crianças que enxergam, mas ainda há carências de investigações sobre as representações elaboradas por crianças cegas. 


\section{CONCLUSÕES}

Os desenhos ou grafismos são um tipo de linguagem presente em nossa cultura desde os primórdios. As representações gráficas são a primeira escrita da criança e são repletos de elementos referentes ao desenvolvimento motor e cognitivo, cultura e afetividade do sujeito que o elabora. A criança desenha para conhecer o espaço, seus esquemas gráficos são representações dos objetos, por isso, ela não se preocupa com a aparência do desenho, mas com o significado que ele possui. O desenho possui uma função comunicacional e deve ser analisado levando em consideração o contexto em que foi produzido.

Os estudos de desenhos de alunos cegos como forma de representação de suas imagens mentais ainda são escassos. Muitas pessoas consideram o desenho como uma atividade imposta pelos normovisuais. A partir do momento em que o desenho da criança cega passa ser considerado como função de sua expressão motora, ele torna-se um recurso para que a criança cega expresse suas imagens mentais.

Para compreender $\mathrm{o}$ ato de desenhar dos alunos cegos, procurou-se referencial teórico em áreas além da Geografia, como Artes Visuais e Plásticas, e Psicologia; e destaca-se que, assim como para a criança normovisual, o desenho pode auxiliar no desenvolvimento cognitivo da criança cega e ele pode ser visto como uma representação do que ela percebe e sente. Portanto, as formas dos desenhos são irrelevantes, o que importa são os significados das representações e sua coerência com o real.

Observou-se que as relações sociais estão fortemente presentes nos desenhos elaborados pelos alunos cegos. A representação do trajeto de suas casas até às padarias eram carregados de informações atributivas por isso; era de suma importância dar voz e ouvi-los para a compreensão da enunciação de seus desenhos.

As análises dos resultados indicam que em sua representação, os sujeitos utilizaram a distância funcional, organização configuracional, relações espaciais entre os objetos, como vizinhança, posição, localização, ordem, envolvimento, continuidade, simbologia, redução proporcional, integração, interligação, informações atributivas. Esses conceitos podem ser utilizados para mediar conceitos cartográficos como escala, orientação, legenda e representação bidimensional.

Conclui-se que é importante trabalhar com locais próximos ao cotidiano dos educandos cegos e partir de situações problemas que os instiguem a refletir sobre as relações espaciais entre os objetos.

\section{REFERÊNCIAS}

ALMEIDA, R.D. Cartografia e Infância. In: VI Colóquio de Cartografia para Crianças e II Fórum Latino-americano de Cartografia para Escolares. Juiz de Fora - MG. 2009. Disponível em<http://www.scribd.com/doc/21198272/Cartografia-e-

infancia?secret_password=1y7uc0bv6objyzc80osp> Acesso em: setembro de 2016.

ALMEIDA, R.D. Do desenho ao mapa: iniciação cartográfica na escola. São Paulo: Ed. Contexto, 2006. 
AMIRALIAN, M.L.T.C. Compreendendo o cego: uma visão psicanalítica da cegueira por meio de desenhos-estórias. São Paulo: Casa do Psicólogo, 1997.

ARHEIM, R. Arte e Percepção visual: Uma Psicologia da visão criadora. Tradução: Ivonne Terezinha de Faria. - São Paulo : Pioneira Thomson, 2005.

CARDEAL, M. Ver com as mãos: a ilustração tátil em livros para crianças cegas. Dissertação (Mestrado em Artes Visuais) Centro de Artes. Universidade do Estado de Santa Catarina. Florianópolis, 2009.

COELHO, L.; PISONI, S. Vygotsky: sua teoria e influência na educação. Revista Modelos FACOS/CNE C Osório. v.2; n2, 2012. Disponível em http:// facos.edu.br/publicacoes/revistas/eed/agosto_2012/pdf/vygotsky_sua_teoria_e_a_influencia _na_educacao.pdf. Acesso em: abril de 2015.

DARRAS, B.. La modélisation sémiocognitive a l'épreuve des résultas des neurosciences. Le cas de la production des schémas graphiques. Recherches en Communication. n.19, p.175-197, 2003. Disponível em: <http://sites.uclouvain.be/rec/index.php/rec/article/viewArticle/5251>. Acesso em: outubro de 2016.

DUARTE, M.L.B . O caso de Manuella e os desenhos-palavras. Revista de Investigação em artes, [s.I.], v. 1, p. 1-15, agosto de 2007.

DUARTE, M.L.B. A importância do desenho para crianças cegas. In: NOGUEIRA, R.E. (Org). Motivações Hodiernas para ensinar Geografia: Representações do espaço para visuais e invisuais. Florianópolis: Nova Letras, 2009.

DUARTE, M.L.B. Desenho infantil e aprendizagem - novos parâmetros. Anais do Congresso ibero-americano de Educação Artística, Portugal, 2008.

DUARTE, M.L.B. O desenho como elemento de cognição e comunicação: ensinando crianças cegas. In: $27^{a}$ REUNIÃO DA ANPED, 2004, Caxambu. Anais... Petrópolis: [s.n.], 2004. p. 270-271. Disponível em: <www.anped.br > Acesso em: outrubro de 2016.

DUARTE, M.L.B.; VALENTE, D. Os objetos e o desenho tátil. Texto apresentado no Relatório de Pesquisa, Centro de Artes. Universidade do Estado de Santa Catarina, 2005. Disponível em: <http://www.batezat-blind.pro.br/>. Acesso em: junho de 2016.

GOMES, L.V.N. Desenhando - Um Panorama dos Sistemas gráficos. Santa Maria: Ed. UFSM, 1998.

GRUBTIS, S. A casa: cultura e sociedade na expressão do desenho infantil. Revista Psicologia em Estudo.V.8 n.1 p. 97-105. Maringá, 2003.

GUYTON, A. Fisiologia Humana. São Paulo: Guanabara Koogan, 1996.

HUERTAS; J.A; OCHAÍTA, E.; ESPINOSA, M.A. Mobilidade y Conocimiento Espacial en Ausencia de la Visión. In: ROSA, A.; OCHAÍTA, E. (Org.). Psicologia de la Cegueira. Madrid: Alianza Editorial, 1993.

JULIASZ, P.C.S; ALMEIDA, R.D. A representação espacial na Educação Infantil sob a ótica da teoria Sócio-cultural e das relações tempo-espaço-corpo. Anais... XXIV Congresso Brasileiro de Cartografia, Aracaju, 2010. Disponível em: <http://arquivo.sepq.org.br/IVSIPEQ/Anais/artigos/13.pdf> Acesso em: outubro de 2016. 
JULIASZ. P.C.S. Tempo, espaço e corpo na representação espacial: contribuições para a educação infantil. Dissertação (Mestrado em Geografia). Instituto de Geociências e Ciências Exatas, Universidade Estadual Paulista, Rio Claro, 2012.

KELLER, H. A história da minha vida. Rio de Janeiro: José Olympio, 2008.

KENNEDY, J. M. What can we learn about pictures from the blind? Blind people unfamiliar with pictures can draw in a universally recognizable outline style. American Cientist, US, v.71; 19-26, jan-fev, 1983.

LEME, M.E.S. A representação da realidade em pessoa cega desde o nascimento. 2003. Dissertação (Mestrado em Educação) - Faculdade de Educação, Universidade de Campinas, Campinas, 2003.

LUQUET, G.H. O desenho infantil. Tradução: Maria Teresa Gonçalves de Azevedo. Porto: Ed. Minho, 1969.

MARTINEZ, J.A.H. Estudio Evolutivo y microgenetico de la representacion espacial y la movilidad en el entorno en los niños y adolescentes ciegos. 1989. Tese (Doutorado em Psicologia) Universidad Autonoma de Madrid, Madrid, 1989.

MORAIS, D.F.P . A formação da imagem mental e a representação gráfica de alunos cegos precoces e tardios: um relato de experiência. 2009. Disponível em: http://sistemas.virtual.udesc.br/cursos/encontro/03_artes_visuais.pdf. Acesso em: outubro de 2016

REGO, T.C. Vygotsky: A aprendizagem no processo sócio-histórico. Petrópolis. Vozes, 1995.

RUBAYO, S.C. Discapacidad y destrezas manipulativas. Madrid: ONCE, 2007. Disponível em

<http://www.redage.org/sites/default/files/adjuntos/Discapacidad\%20visual\%20y\%20destrez as\%20manipulativas.pdf> Acesso em: agosto de 2015.

SCHROEDER, E. Conceitos Espontâneos e Conceitos Científicos: o processo da Construção Conceitual em Vygotsky. Atos de Pesquisa em Educação (FURB), v. 2, p. 2, 2007.

SILVA, S.M.C. Condições Sociais da constituição do desenho infantil. Psicologia USP, v.9, n.2, p. 205-220, São Paulo, 1998.

VALENTE, D. O desenho como ferramenta de comunicação para pessoas cegas: estudo sobre a influência do contexto perceptivo na compreensão de representações gráficas esquemáticas. In: Anais... CONGRESSO IBEROAMERICANO DE EDUCAÇÃO ARTíSTICA, Beja, 2008.

VALENTE, D. Os diferentes dispositivos de fabricação de imagens e ilustrações táteis e as possibilidades de produção de sentido no contexto perceptivo dos cegos. Revista Educação, Arte e Inclusão, Florianópolis, v. 2, 2010.

VENTORINI, S. E. Representação gráfica e linguagem cartográfica tátil: estudo de casos. São Paulo: Unesp, 2014. $195 \quad$ p. Disponível em: $<$ http://www.editoraunesp.com.br/catalogo/9788568334201, representacao-graficaelinguagem-cartografica-tatil> . Acesso em: julho de 2015. 
VENTORINI, S. E.; SILVA, P. A.; FREITAS, M.I.C. Cartografia Tátil: Teoria e Prática. In: FREITAS, M.N.C. Inclusão: possibilidades a partir da formação profissional. São João delRei: Ministério da Educação, 2015. p. 93-116. Disponível em: < http://www.ufsj.edu.br/portal2-repositorio/File/proex/INCLUSAO/E-

BOOK\%20INCLUSAO\%20Possibilidades $\% 20 \mathrm{a} \% 20$ partir $\% 20$ da $\% 20$ formacao $\% 20$ profission al\%20-\%20final.pdf> . Acesso em: junho de 2016.

VENTORINI, S. E; SILVA, P. A. ; ROCHA, G. F. S. CARTOGRAFIA TÁTIL E A ELABORAÇÃO DE MATERIAL DIDÁTICO PARA ALUNOS CEGOS. Geographia Meridionalis, v. 2, p. 268-290, 2015.

VENTORINI, S.E. A experiência como fator determinante na representação espacial do deficiente visual. 2007, v. 2. Dissertação (Mestrado em Geografia) - Instituto de Geociências e Ciências Exatas, Universidade Estadual Paulista, Rio Claro, 2007.

VENTORINI, S.E. A experiência como fator determinante na representação espacial da pessoa com deficiência visual. São Paulo: Ed. UNESP, 2009.

VENTORINI, S.E. Representação gráfica e linguagem cartográfica tátil: estudo de casos 2012. Tese (Doutorado em Geografia) Instituto de Geociências e Ciências Exatas, Universidade Estadual Paulista, Rio Claro, 2012.

VIGOTSKY, L.S. A construção do pensamento e da linguagem. São Paulo: Martins Fontes, 2001.

VIGOTSKY, L.S. A Formação social da mente: o desenvolvimento dos processos psicológicos superiores. Trad. José Cipolla Neto et al. São Paulo: Martins Fontes, 1991.

VIGOTSKY, L.S. Fundamentos de defectologia. Trad. Lic Maria del Carmem Ponce Fernadez.In: Obras completas. Tomo V. Havana: Editorial Pueblo y Educación, 1997.

VIGOTSKY, L.S. Obras Escogidas V: fundamentos de decfetologia. Edición em la lengua castellana, 1983.

VIGOTSKY, L.S. Pensamento e linguagem. Tradução Jeferson Luiz Camargo. São Paulo: Editora Martins Fontes, 1989.

WALLON, P.; CAMBIER, A.; ENGELHART, D. Le dessin de l'enfant. França: Press Universitaires de France, 1990.

WARREN, D. Blindness and children: an individual differences Approach. Cambridge: Cambridge University Press, 1994. 